A second feature which was but slightly marked in the present case but was very marked in one of my other cases is a large brachycephalic skull and especially a fullness or bulging in the temporal tossa. (Ludford Cooper, Trans. Ophthal. Soc. U.K., 1906, XXVI, 136).

In one of my cases this was so marked as to appear as if the squamous bone in particular were being pushed outwards by some tumour within, and in another case although the prominence was less extreme the man had been trephined over the area, perhaps with the expectation of finding a tumour.

In addition to the bony bulging in the temporal fossa, it is common in those cases with large pendulous upper lids due to a plexiform neuroma to find that this condition has extended into the temporal fossa causing a doughy sort of swelling there. (Treacher Collins and Rayner Batten, Trans. Ophthal. Soc. U.K., 1905, XXV, 248, and Snell, Trans. Ophthal. Soc. U.K., 1903, XXIII, 157).

With regard to the skin tumours, if the present patient's observation may be trusted, they first showed themselves about 15 years ago, that is at the age of 18 years, about 12 or 15 years after the development of the proptosis. The presence of the opaque nerve fibres in the left retina may be no more than a fortuitous occurrence; on the other hand it seems likely that they are in some way connected with the abnormality of the other nerves of the body.

I have especially to thank my House Surgeon, Mr. E. G. Recordon, for the details of the clinical history and the general overhaul of the patient, and for obtaining the plaster cast and measurements of the skull.

\title{
ANGIOID STREAKS, AND THEIR RELATION TO A FORM OF CENTRAL CHOROIDAL DISEASE
}

BY

\author{
RAYNER D. BATTEN
}

LONDON

THIS selection of drawings from Hamblin's collection, together with the family which I report, while of interest in itself, is, I consider, important in the evidence it affords in confirming and consolidating the observations of others on angioid streaks and their relation to a special form of choroidal disease, and in establishing it as a definite disease, with special characteristics of its own, frequently familial in causation. 


\section{The British Journal of Ophthalmology}

CaSE 1. (Drawings 1 and 2). Seen in May, 1928.

Mrs. M., aged 52 years, sister to the two following cases.

Ten years ago, her sight failed suddenly in both eyes, for near and distance, and has remained the same ever since-she had only noticed a slight mistiness for distance vision previously.

No head-aches; no eye-aches. General health very good. No general medical history obtained.

Married 21 years; does all her own work; goes about alone; sews and writes, but cannot read. When the eyes were first affected, she attended Moorfields, but does not recollect under whose care.

V. Right $2 / 60$. Left $<1 / 60$.

Ps. = react. T.n.

Her visual fields are full, but she is unable to fix a central spot.

Right fundus shows widespread white choroidal atrophy or thinning all round O. D. On both temporal and nasal sides, there are islands of red choroid.

The chief disturbance is at the macula, where there is a dark mass of pigment similar to the "black spot macula" found in myopes, and presumably due to the same cause, viz. a macular haemorrhage.

There are also scattered patches of pigment, some superficial retinal, and some deeper pigmentation of a brownish red colour. There are no actual angioid streaks, but the deeper pignentation is of much the same colour.

The left fundus resembles the right closely, but there is no black spot at the macula. Beyond the macula, there is a dense white crescent-shaped mass, superficial to the retina, ending in the feathery tails of retinitis proliferans. The scattered pigmentation is of the same character as in the right eye, both superficial and deep pigmentation. No angioid streaks were detected. I would suggest that there may have been angioid streaks, which have become absorbed, and are represented by the more diffuse pigmentation.

\section{C.ISE 2. (Drawings 3 and 4 )}

C. N., aged 42 years, a brother of the first case, 10 years younger. I got him to come and see me in May, 1928. His sight had begun to fail three years previously, when he appears to have had a scotoma gradually encroaching on his central vision in the right eye. It appeared as if something was " chipped out" of the thing he looked at on the right hand side, and it gradually extended, covering half the eye.

In January, 1927, he was seen by Mr. Gayer Morgan, who showed the case at the Ophthalmic Section of The Royal Society of Medicine. I have been unable to obtain his full medical history. $\mathrm{He}$ is a spare healthy-looking man, with no family resemblance to his brother. He reports himself quite strong till 16 years ago, never quite strong since. He is said to have V.D.H. His W.R. is negative.

His right fundus shows marked angioid streaks, chiefly to the nasal side of the O.D.running vertically on the temporal side of the O.D. between the macula and the O.D. There is a patch of choroidal exudate in conjunction with an angioid streak, though not interrupting its course. The patch is nearer the macula than shown in the drawing and more triangular in shape.

In the left eye, the angioid streaks are more marked and on the nasal side of the optic disc. There is a small patch of choroidal exudate with pigmented margin directly in the course of an angioid streak, which it interrupts but does not divert. There are no definite haemorrhages.

His visual fields show a nearly full field in his right eye, except for slight constriction to the temporal side above, with a large central scotoma.

His left field is more constricted to the temporal side and above.

V. Right $:<6 / 60$. Left $: 6 / 6$.

Mr. Morgan ${ }^{6}$, when showing this case before the Section in 1927 , reported as follows :-

Patient, a male; aged 39 years.

First seen, August, 1925, when he complained that straight lines were slightly dented when seen by the right eye. V. 6/6 in each eye.

Both fundi showed marked angioid streaks, peripheral patches of old choroidal scarring, faint pigmentary changes at both maculae, but no haemorrhage or exudate. 


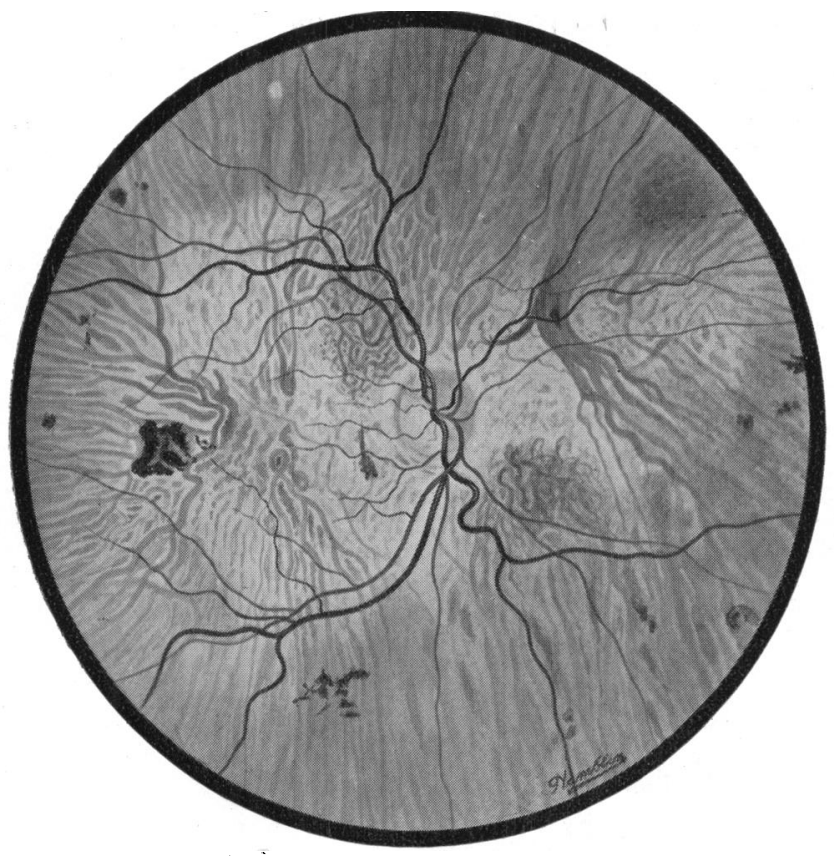

DRAWING 1.

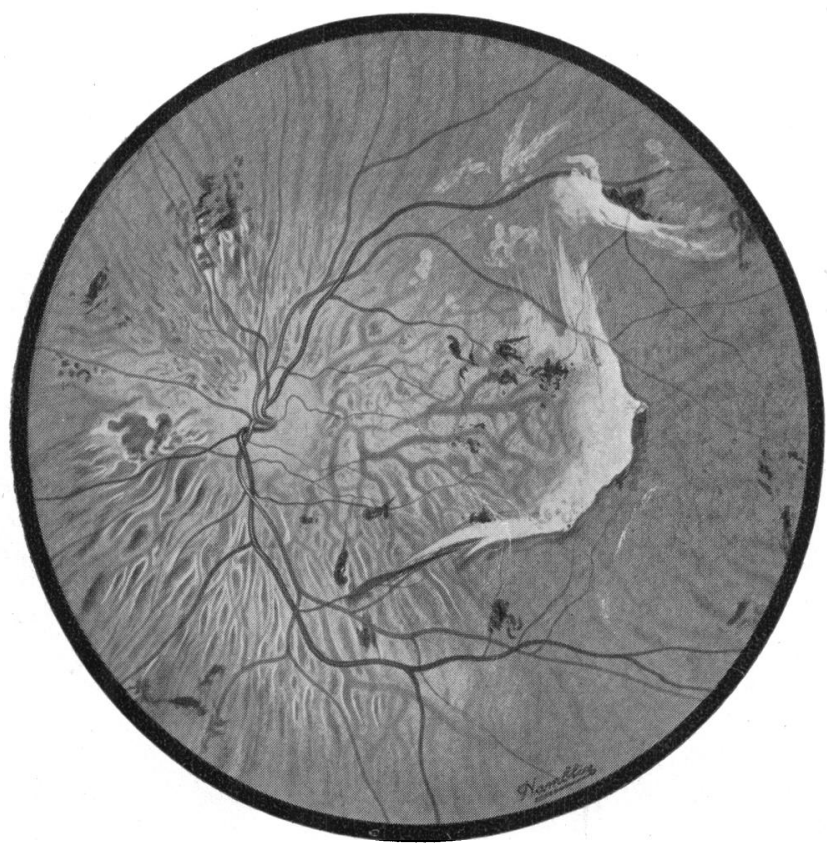

DRAWING 2.

Note on CASE 1 -Drawings 1 and 2.

The changes here are typical of an advanced stage of this disease, and should be compared with those shown in 5 and 6 (her brother), also with $9,10,11,12$ and 13

Changes of a similar character are found in other publisbed drawings, notably those of de Schweinitz, Doyne, and others.

Note the pigmentation in scattered masses, the central choroidal thinning, disturbance, and the retinitis proliferans. But there are no angioid streaks. 


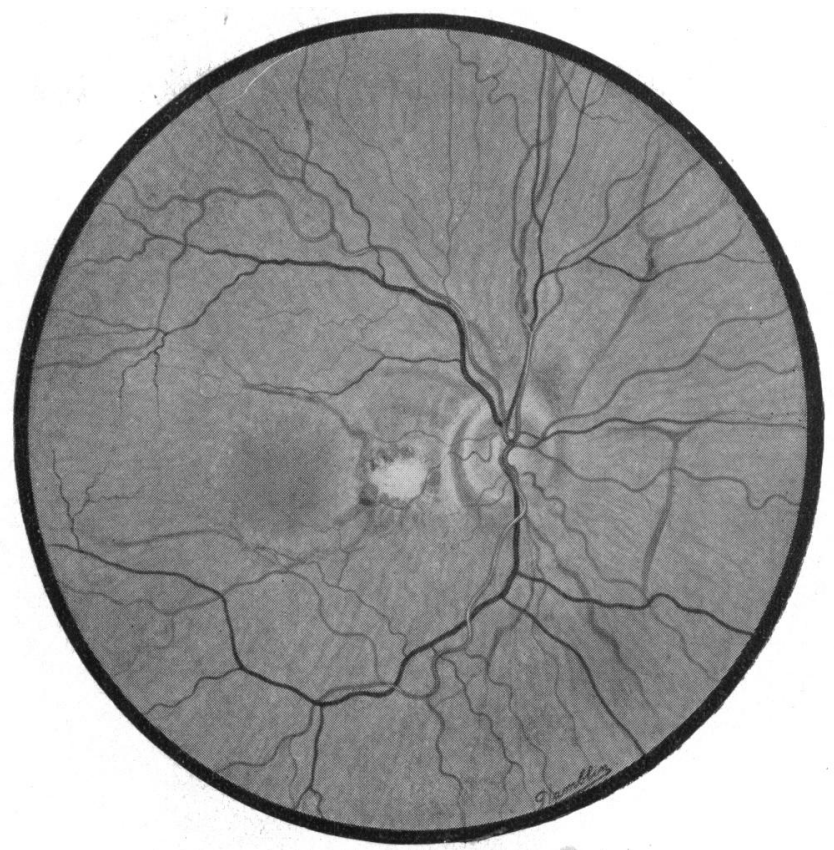

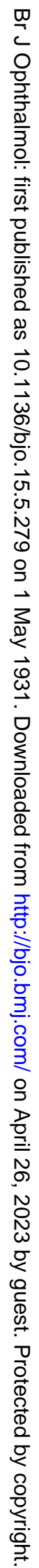

Drawings 3 and 4 are from the brother of Case 1. Show typical angioíd streaks in both eyes. Note the choroidal spot in No. 4, interrupting the course of the angioid streak, and compare with Drawings 6, 13, and 14. 


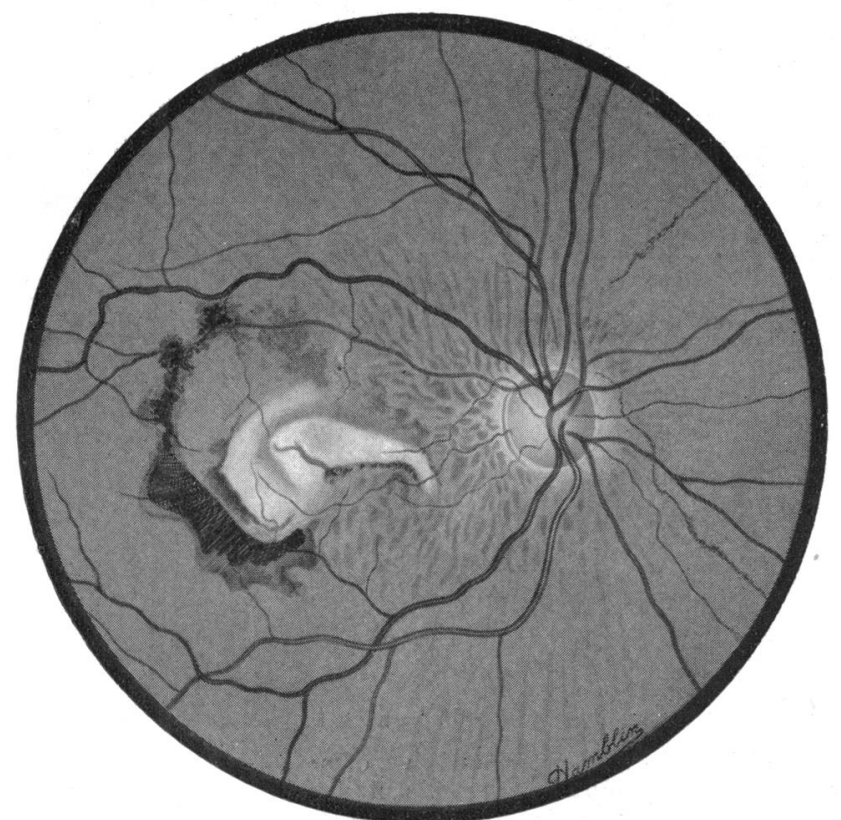

DraWING 5, CASE 3, 1928.

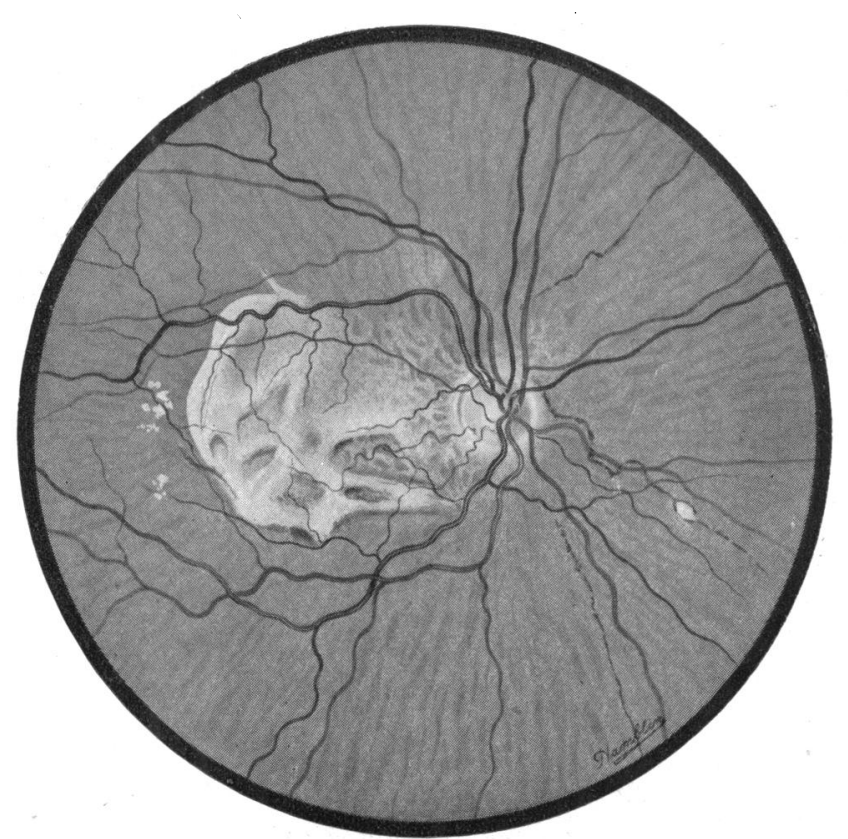

Drawing 6, Case 3, 1929. 


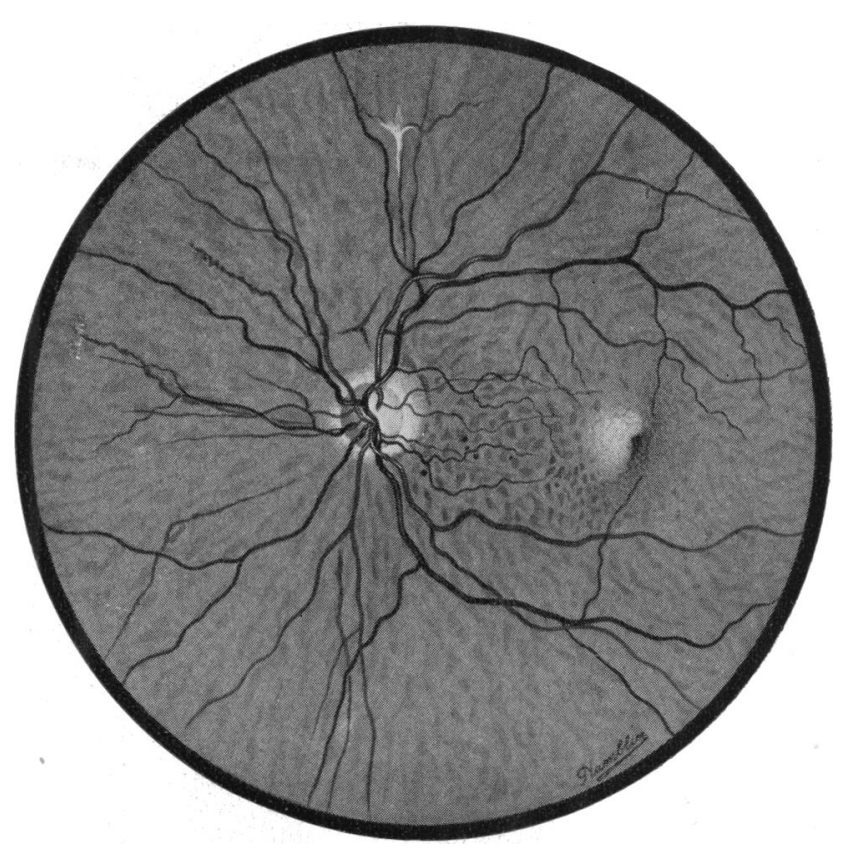

Drawing 7, CASE 3 .

Note on CASE 3-Drawings 5 and 6 (right eye), 7 (left eye)

Drawings 5 and 6 show the stages of the formation of the central choroidal disease, with small patches of retinitis circinata. Compare Drawing 11. Drawing 7.- Note the macular pigmentation and disturbance. Drawing 5 was made in May, 1928. Drawings 6 and 7 were made in March, 1929.

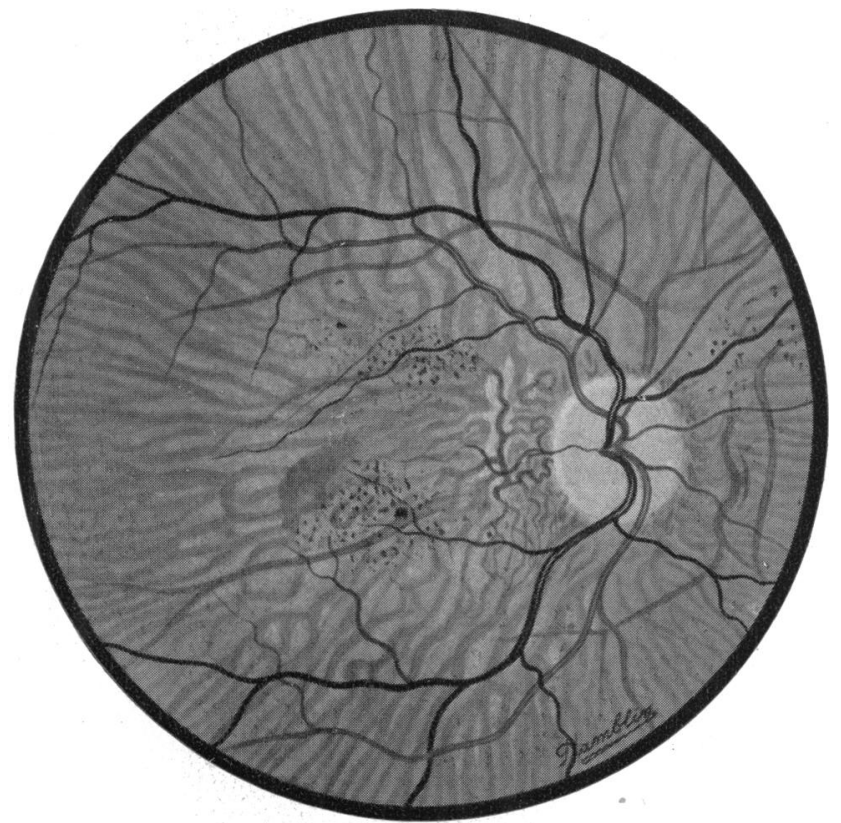

Drawing 8, Casi: 4.

Note ON CASE 4.

The drawings in colour of the left eye. No. 1 was drawn in February, 1924. No. 2 was drawn August, 1930 . No. 1 shows typical angioid streaks and central pigment changes, with a small haemorrhage just below the macula. No. 2 shows typical central choroidal changes and gross pigmentation. Drawing No. 8, right eye of the same pattent, shows typical pigment changes and angioid streaks. The drawing was made in 1930 and shows but little change from the previous drawing in 1924. 


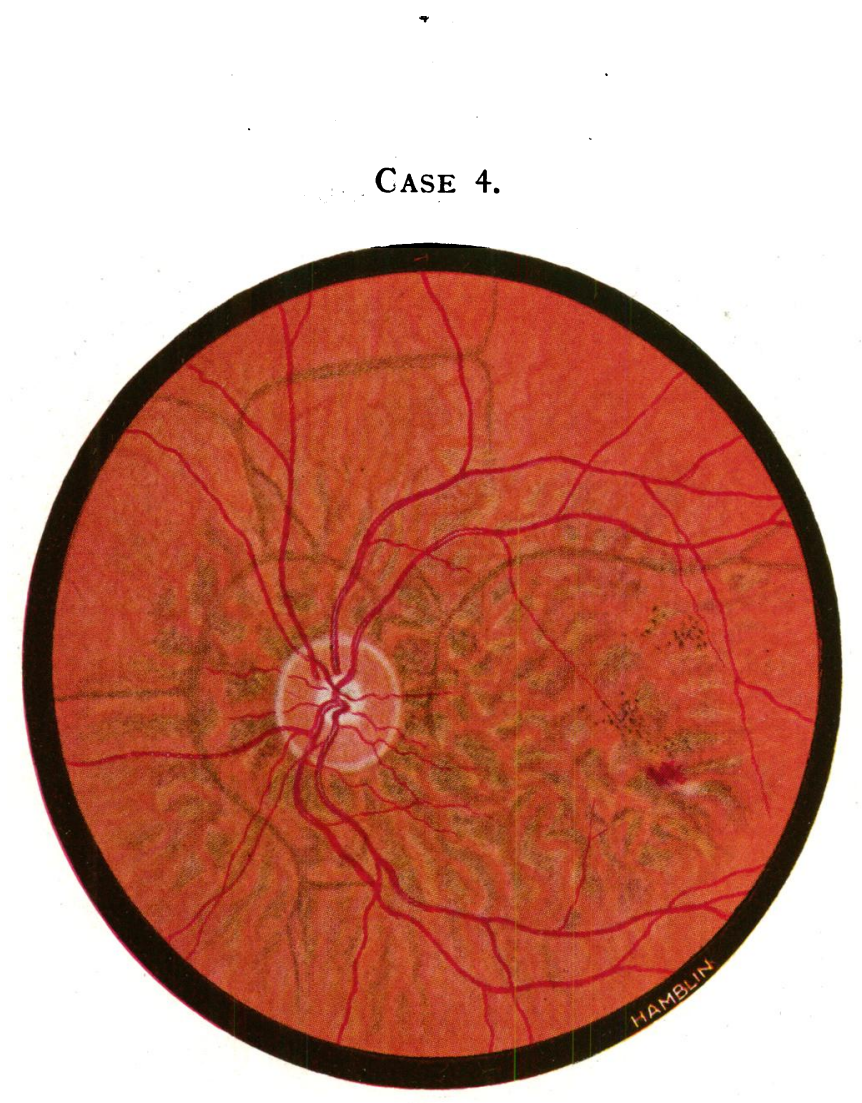

$\underline{\underline{m}}$

c

음

宗

$\frac{0}{3}$

음

ज

믐

DraWing 1, FEBRUARY, 1924.

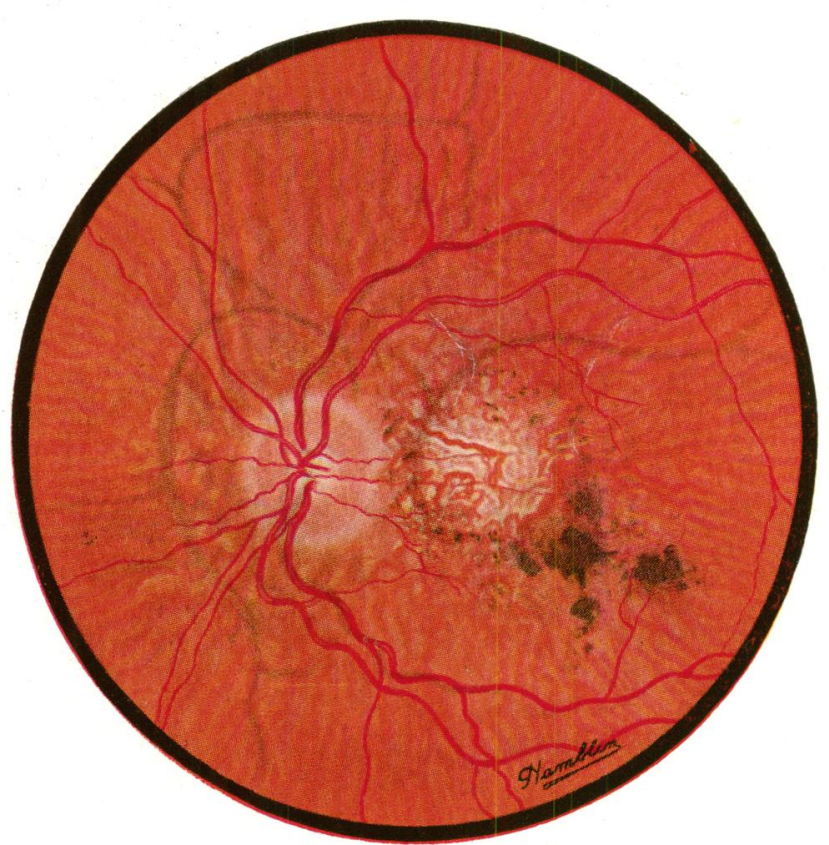

Drawing 2, August, 1930.

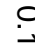

ज़

음

ज

ir

กิ

음

군

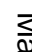

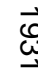

응

产

ํํำ

용

흠

量

흥

호․

ㅇํㅀ

옥

금

N

\%

N

No

包

을

$\stackrel{\Phi}{\mathscr{D}}$

7

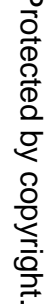




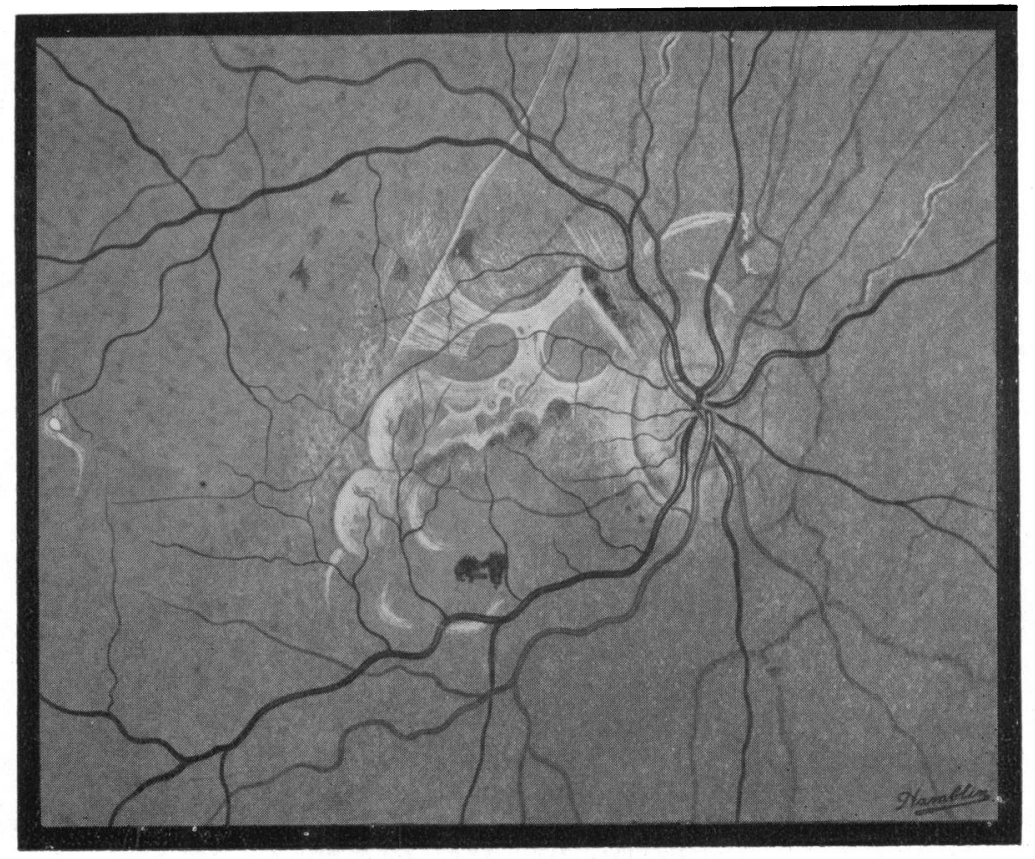

DRAWING 9.

Note on CASE 5.

Drawing No. 9.-Right eye shows typical central choroidal changes, scattered haemorrhages, and angioid streaks. The dark spots are haemorrhages, not pigmentation. The left eye was similar.

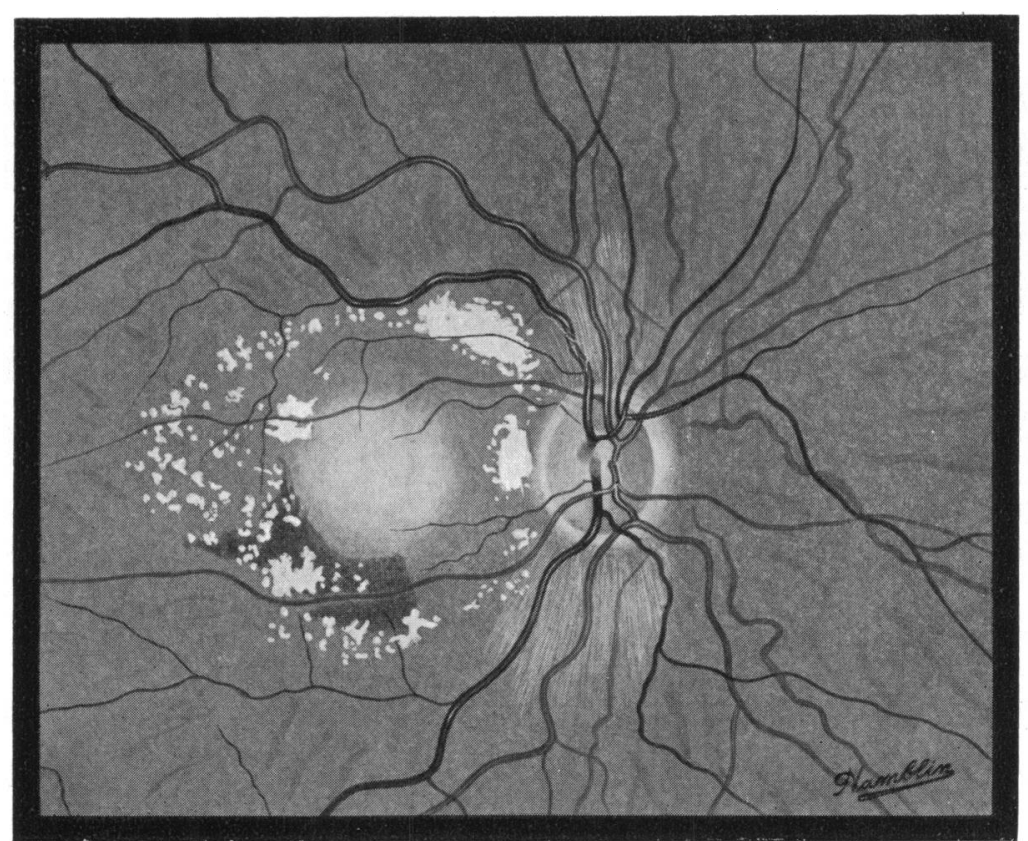

Drawing 10, Case 6. 


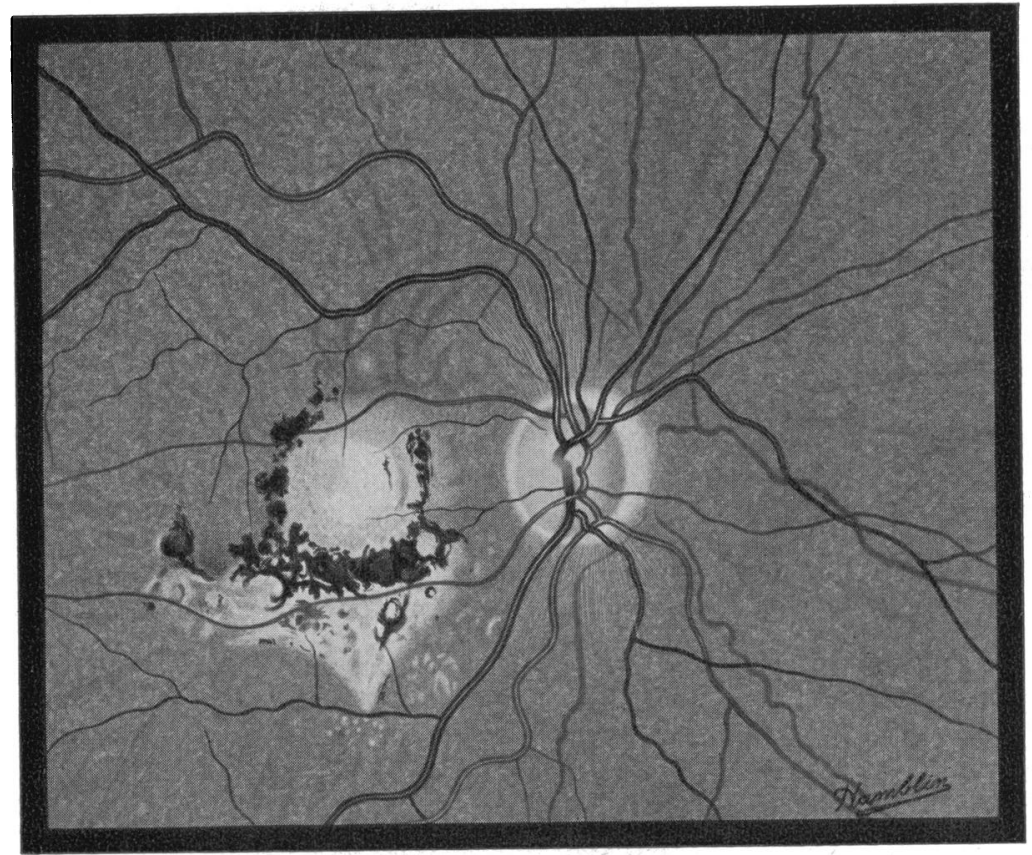

DRAWING 11 .

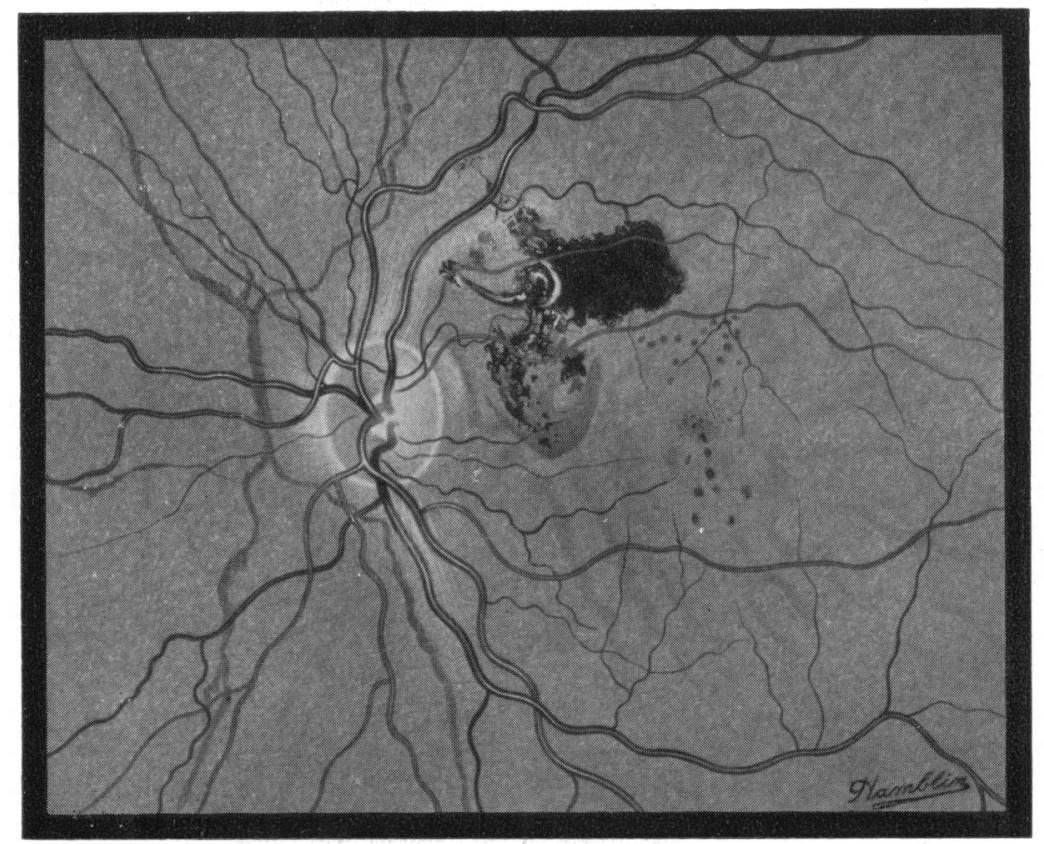

DRAWING 12.

Note ON CASE 6-Drawings 10, 11, and 12 .

10 and 11 are drawings of the right eye at different stages, a month apart. Note the retinitis circinata in 10 and the gross pigmentation in 11 , with central choroidal changes. Drawing 12 shows gross pigmentation above and typical fine pigmentation at and round the macula. Angioid streaks are abundant in both eyes. 
Seen again in October, $1926, \mathrm{~V}$. in right $6 / 60$, left still $6 / 6$.

The right fundus showed an angioid streak passing through the macula, white patches of exudate round the macula, resembling those seen in retinitis circinata, and minute punctate haemorrhages in the deeper layer of the retina.

This is the point of interest in the case as it supports the view that, even if the streaks are not vessels, they are associated with vascular disturbances in the deeper layer' of the retina or choroid, and are closely related to retinitis circinata and Coats's disease.

CASE 3. (Drawings $5,6,7$ )

I first saw this patient in April, 1928.

S. N., aged 41 years, butcher. Brother of the two preceding cases.

History. - His sight had been failing since 1923, which he attributed to fatigue after a long drive in a car.

Three years ago, he received a blow on the right eye from a piece of bone whilst chopping meat; the eye was painful for a few days, but he did not notice anything else. The sight in the right eye has got worse lately.

$\mathrm{He}$ is a strong robust-looking man-he is a butcher by trade and looks it-drinks up to 10 whiskeys a day, smokes 25 cigarettes a day.

No septic trouble found in throat, nose, or teeth.

He has had no illnesses beyond minor ailments of childhood, and appendicitis, for which he had an operation.

The report on his heart states, reduplication of 1st mitral sound, B.P. 140/85. Pulse full, regularly irregular 96 per min.- - urine normal.

The blood count shows no evidence of any pathological change and is regarded as normal. The W.R. is negative.

He had difficulty in reading. He can see to drive a car in daylight but not at night (subsequently he ran over and killed a man).

The family history is important.

His mother has good sight-a sister of her's has been blind since birth.

The family consists of six members.

Sister aged 52 years. Sight failed suddenly in both eyes, 10 years ago.

Sister aged 47 years. Good sight.

Brother aged 45 years. Good sight.

Brother aged 42 years. Sight failed three years ago.

Patient aged 41 years. Sight failed one year ago.

Brother, aged 35 years, good sight.

On examination Ps. = active $\mathrm{T}$. normal.

V. right $<6 / 60<$ J.14. Left $6 / 9$ J.1 slowly and with difficulty.

There is no error of refraction.

His visual fields, right and left, show some constriction on the temporal side.

Right eye no colour-perception. Left, partial central scotoma for colours.

Fundi.-Right O.D. slightly blurred margin; central vessels appear raised but no measurable swelling. There is a pale area surrounding the disc.

The choroid between the O.D. and macula has a mottled appearance.

The central macular area is occupied by a dense scarred area, buff coloured, " tadpole" "-shaped, with its tail towards the O.D., and beyond this another pale area, and beyond this again a semi-circular area of recent haemorrhage of the subhyaloid type.

There is a brown pigmented line running along the lower margin of the tail, resembling an angioid streak, and two definite angioid streaks to the nasal side of the O.D.

The left fundus resembles the right in the peculiar pale area round the O.D. and the fine mottled appearance of the choroid between the O.D. and macula.

There is a slight blurring of the O.D. and there is some disturbance at the macula. The angioid streaks were not noted at the first examination, but, when seen again at the end of April, I noted right and left O.D. slight optic neuritis and angioid streaks in both eyes.

The first drawings of his fundi were made in May, 1928, and by then the angioid streaks were quite definite in both eyes. He was seen again in July, 1928; the chief change was in the haemorrhage in the right, which was tending to break up into islands. 
The second drawings were made in March, 1929. In the right eye the haemorrhage had absorbed, and left a dense mass continuous with the former central mass, with a second tail below, extending towards the lower part of the O.D. The pigmented angioid streak at the lower border of the first tail is less visible, presumably covered by the exudate. The retinal vessels pass over it and do not appear to be deflected by it-no raising or swelling of the mass was detected-otherwise it has some resemblance to the senile massive exudates. There are a few spots of exudate beyond its outer margin, suggestive of retinitis circinata. There is also a white spot, choroidal exudate or haemorrhage, to the nasal side of the O.D. lying in the course of an angioid streak which it interrupts-the streak resumes its course beyond the spot.

In the left eye, the angioid streaks appear more numerous. This may partly be due to more careful searching for them. The macula is definitely pigmented. There are also some fresh pigment-spots near the O.D.

Case 4. (Coloured plate, left eye, and drawing No. 8, right eye).

Miss A. R., aged 41 years.

First seen in February, 1924. First noticed some difficulty in seeing with the left eye in Octuber, 1923 ; previously, the right eye had always been the weaker.

Physical Examination.-Medical report negative. General health appears very good; she plays, tennis and used to play hockey. Her neck is remarkably thin and there is apparent absence of any trace of thyroid. She is grey-haired since about the age of 24 years and is getting more so. The teeth were extracted in November, 1923 , on account of her eyesight.

The possibility of syphilis is ruled out by her medical attendant.

The family history has been enquired into and is negative. This enquiry was made on account of the retinal pigmentation in and surrounding the macula, which I considered familial in type, and not because of the angioid streaks, the familial significance of which I was not familiar with at that time.

P. $=$ active; T.N. R.V. $-2 \cdot 0$ D. sph. $+2 \cdot 0$ D. cyl. $30^{\circ}=6 / 12 \times$ J.1:

Left -1.50 D. sph. $+1 \cdot 0$ D. cyl. $190^{\circ}=6 / 18$; letters in J.10 but J.12.

Fundi, right and left eyes, marked angioid streaks in both eyes, chiefly to the nasal side of the O.D.; where they run, they tend to encircle the O.D. On the temporal side they tend to follow the direction of the retinal vessels. The streaks run under the retinal vessels in several places. There is marked fine retinal pigmentation scattered over the central area, coarser in the right than in the left, but coming closer to macula in the left.

In the left, there is a small macular haemorrhage. Seen again two months later, the haemorrhage was absorbing and the vision slightly improved.

The visual fields were full. There was a central scotoma in the left eye, extending upward from the fixation point.

I saw this patient again in August, 1930, when she reported that her sight had remained satisfactory until April of that year, when the central vision failed in about the course of two weeks. The vision is now reduced to:- Right 6/24, left $<6 / 60$.

In the right eye, there is but little change in the ophthalmoscopic signs to account for the failure of vision. But in the left, there is an extensive area of choroidal atrophy between the O.D. and the macula, with gross retinal pigment change.

The choroidal atrophy and pigmentation in this case are, I consider, typical of this disease, when compared with the central choroidal atrophy in the other cases.

It will be seen from the foregoing cases that the onset of the disease occurs in middle-life, between the ages of 30 and 40 . The familial tendency to disease at this comparatively late period of life is interesting, as each case taken by itself might be supposed to be due to some acquired disease, and not to any hereditary tendency, but, taken in conjunction with other members of the family, it would appear to be due to the same inherited defect or tendency. The association of the angioid streaks in at least two members of the family may throw some light on the 
clinical aspect of this obscure condition. The fact that angioid streaks are associated with choroidal disease appears to be proved by the reports of other cases.

Holloway ${ }^{1}$ summarizes the evidence of a familial disease associated with the formation of angioid streaks as follows :-

"No definite statement has been made up to this time concerning heredity among the 60 cases of angioid streaks reported. Examples of this have been seen on four occasions ; first, in 1897, by de Schweinitz, who observed two brothers (and suspected a third) with the condition; in 1914, by Spicer, who described the changes in a brother and sister; in 1923, Lederer observed two sisters similarly affected; and finally Wildi, in 1926, found two brothers with the affection. Thus, amongst 56 families, a familial tendency occurred in four instances, an incidence of 7.14 per cent. Even these figures are much too high for a coincidence, especially when we consider that familial characteristics probably were not looked for in half of the cases; if such an investigation had been made, it is possible that the actual incidence would be distinctly higher."

But the evidence for the existence of a familial choroidal disease becomes still stronger, when we bring into the picture the sister of the two brothers I report, and also the sister of the case narrated by Calhoun ${ }^{2}$, both with bilateral choroiditis. It seems more than likely that, if there is a familial tendency, to haemorrhage in the choroid, the same haemorrhagic tendency may be found in other organs in other members of the family. Thus, if inherited disease or weakness of the choroidal vesseis can be established as an entity, it would be reasonable to look for a similar weakness or disease of the vessels in other parts of the body and in other members of the family. This point has been emphasized by Calhoun, writing on "The site of angioid streaks," when he says : "Inasmuch as angioid streaks usually involve both eyes, and as in some instances it has been noted that other members of the family have the same condition, an endeavour has been made to link the eye picture with some constitutional disturbance. Investigations, however, have been futile. The family history of this patient seems to confirm this suspicion, for the death of a brother at an early age from a heart attack, as well as a sister with bilateral choroiditis (which might have been an atrophy from haemorrhage and not an infection) strongly suggest some disease of the vascular system which might be familial in origin." The case of the sister which he reports corresponds to the case of the sister in the family I report, who had extensive bilateral choroiditis of vascular origin, without angioid streaks. This condition would appear to point to a vulnerability or weakness of the vessel walls. 
The points which I hope to bring out by the narration of these cases are :-

(1) That there is a familial disease of the choroidal vessels, shown in its early stages by angioid streaks and other pigmentary changes of choroid and retina, and followed, in some cases, by gross central choroidal haemorrhages, which are again followed by. further retinal and choroidal changes.

(2) That the disease is of slow onset, extending over many years, though its first evidence, bringing it to our notice, may be sudden gross haemorrhage, commonly at the macula, of the central choroidal or subhyaloid type.

(3) That it is a primary disease of the vessel walls and not secondary to any septic or inflammatory disease, though it may be associated with a similar vascular weakness in other parts of the body, in other members of the family, or in the same individual.

(4) That the angioid streaks are definitely of choroidal origin and probably due to a slow " seepage" from the choroidal vessels, and that angioid streaks are not an essential part of this familial choroidal disease, but that it may occur without them, and that, while they are definite evidence of the disease, their absence does not negative the nature of the disease.

(5) That they are associated with other changes, viz: some forms of retinal pigmentation at the macula and choroidal disturbance and pigmentation.

(6) That this choroidal disease may account for many forms of macular haemorrhage of the choroidal and subhyaloid type, and other forms of haemorrhage. Retinitis circinata occurs frequently in this disease and is associated with the macular haemorrhage stage; it tends to absorption with the subsidence of the haemorrhage, and when it persists it is evidence that the macular disease is still active.

(7) There is lack of information as to the after history of these cases, but, so far as it goes, it would appear to be of the same type as hereditary optic atrophy and neuritis, in that, its acute stage having been passed, the disease does not progress and the patients do not become blind; but this point requires further investigation.

I would suggest that the causation of these cases is best explained, clinically, by assuming that there is a slow form of oozing, or " seepage," from the choroidal vessels, without gross haemorrhage, but allowing blood to percolate through the vessel walls along the course of the choroidal vessels, giving rise to the angioid streaks, and that the same vascular weakness would account for the various forms of retinal and choroidal disturbance of pigment, found in this disease. "Seepage" may account for many obscure macular conditions without angioid streaks which 
lack explanation of their causation, including some of the familial macular diseases. I would suggest that in investigating familial eye-disease it is important to carry one's investigation of the disease beyond the confines of the eye. Oozing may find its counterpart in haemorrhage from the lung or bowel, in other members of the family.

The evidence would appear to show that the disease is one of the vessel-walls only, and not due to any blood-condition. The weakness of the vessel-walls is further shown in the formation of aneurysmal dilatation, and their liability to gross haemorrhage, either spontaneously, or on slight injury.

Of the various forms of pigmentation in this disease, the most arresting is the angioid streak, but the disease gives rise also to almost all forms of pigmentary disturbance. In the grosser forms of central haemorrhage, the pigmentation may be of all forms, from some large central masses, resembling the "black spot " macula of the myope, to various forms of choroidal and retinal pigmentation. But the most interesting forms are those occurring before any gross haemorrhage has taken place, from the fine macular pigmentation to the small rounded spots seen in drawings Nos. 8 and 12. The fine retinal pigmentation of the macula is perhaps the most constant, and is similar to that of the familial macular disease. It was this condition which led me to examine the family history in Case 4-not the angioid streaks, the familial significance of which was unknown to me at the time.

There is one form of choroiditis peculiar to this disease. Small round choroidal patches occur in the course of the angioid streak, but do not interrupt it; it is continued beyond.

One author, Spicer ${ }^{3}$, describing these peculiar patches, concludes that, as they do not interrupt the course of the angioid streak, they - cannot be any form of vessel. But, if the view be taken that the angioid streak is formed round a choroidal vessel, and if, further, it can be shown that these choroidal vessels are liable to aneurysmal dilatations in their weakened walls, then the patches may be formed by exudate or haemorrhage surrounding the aneurysmal dilatation, and the course of the angioid streak would not be interrupted. Mr. Williamson-Noble's case (drawings 13 and 14) illustrates this point, showing both the enlargement of the streaks with dilatation at certain points, and in the same drawing, patches of this form of choroiditis in the course of the vessels.

\section{Angioid Streaks in their relation to Injury}

The relationship would appear to be rather obscure, and if angioid streaks are due to injury at all, they are a very late result. In the case reported by Doyne ${ }^{4}$, there is a history of traumatism for each eye on separate occasions, and on each occasion the blow 
was followed by temporary loss of vision, with central haemorrhage. It seems probable that the angioid streaks were not produced by the injury, but that the haemorrhage only occurred because of the peculiar condition of the vessels, which rendered them liable to rupture on slight provocation. The angioid streaks were there previously. Also, if traumatism by itself were a cause of angioid streaks, they would surely be much more common in cases of injury than they appear to be, even where a choroidal haemorrhage has taken place.

In one of my cases, there was a history of injury to one eye three years previously, but it is more than doubtful whether the injury caused the angioid streaks, as the injury was to one eye, and the streaks were in both. The same may be said in Mr. Williamson-Noble's case.

\section{Angioid Streaks and Paget's Disease}

In the course of my researches in Hamblin's collection of drawings, I came across a case of Mr. Juler's (drawings 17 and 18) of angioid streaks associated with osteitis deformans (Paget's disease). The connection between the two diseases is worth noting, for F. H. Verhoeff , writing on "The Nature and Pathogenesis of Angioid Streaks in the Ocular Fundus," says :-

"I have recently seen a typical case in a patient with Paget's disease of the skull, but I am not prepared to say that this is of any special significance." The pathology of Paget's disease appears to be unknown, but Da Costa says : "The disease does not appear to be hereditary, although, in 14 instances, 2 or more cases occurred in the same family." There are, therefore, cases suggesting its hereditary or familial nature, and accordingly it is of interest to find a case of angioid streaks associated with this disease ; and in the same connection, Mr. Summers' case (drawing 19) of subhyaloid haemorrhage associated with Paget's disease might be due to this choroidal disease which I am describing. The haemorrhage in his case is typical of this type of disease, although there are no angioid streaks. The concurrence of two such rare diseases can hardly be a matter of pure coincidence, and may throw some light on the pathology of both.

Case 5. (Mr. Percival Hay's Case. Ref. 7). Drawing No. 9.

G. H., male, aged 37 years. Vision R. fingers at 1 foot. Left 6/60.

Exudative retinitis with angioid streaks.

? Coats's disease.

First attendance in June, 1927.

Had an operation for appendicitis two months before.

His health had been poor for some time but improved after the operation.

His sight began to fail in June.

His vision on his first visit was, right fingers at 6 inches. Left 6/60. 


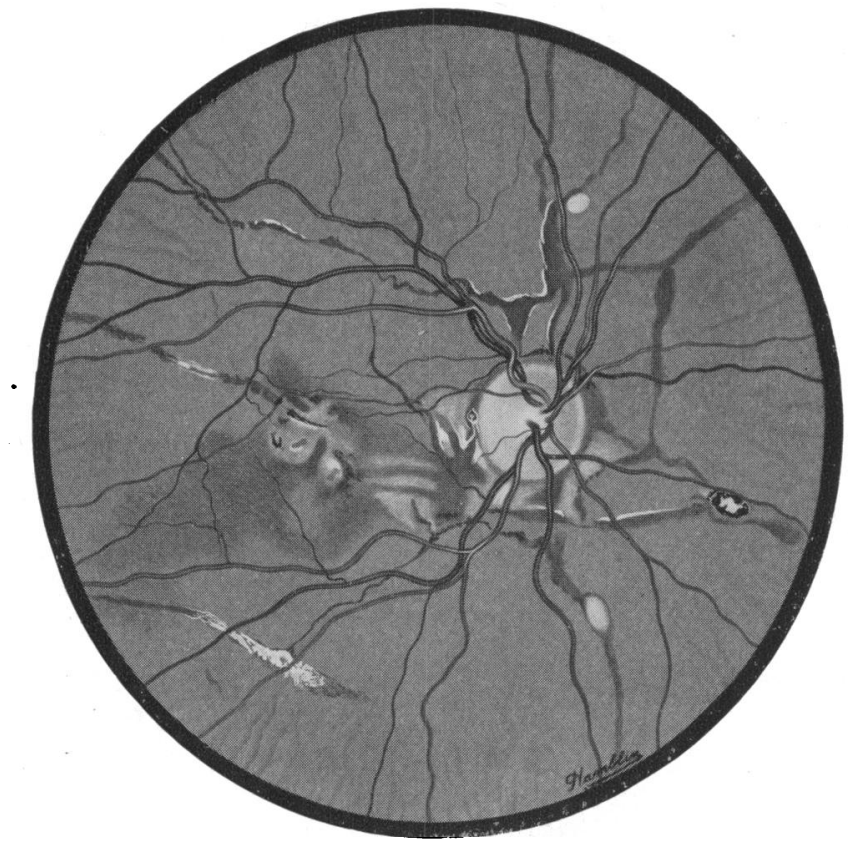

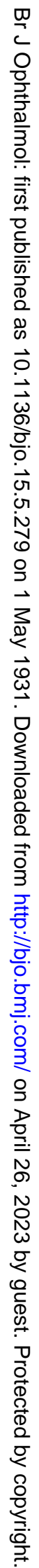

Drawings 13 and 14 show angioid streaks of an unusual type; they are much larger than any others I have found in published drawings, and show dilatation in places. Their colour is lighter and less pigmented than usual. Note the choroidal spots in the course of the angioid streaks. 
Note the choroidal spot in left eye surrounded by angioid streak, and extensive very fine Tay's choroiditis. 


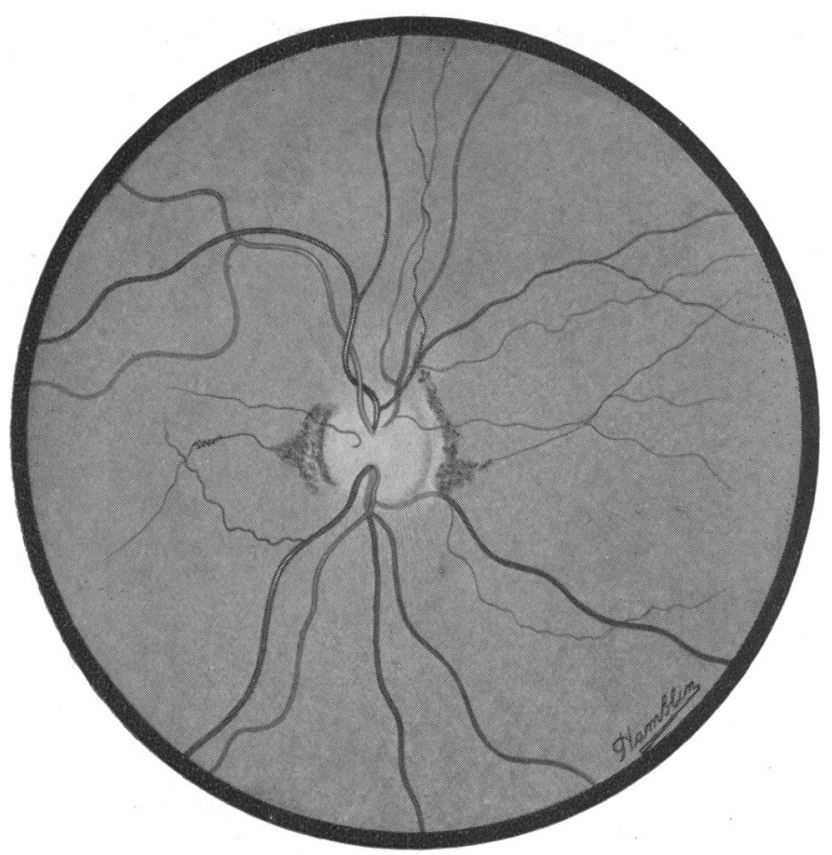

DRAWING 17.

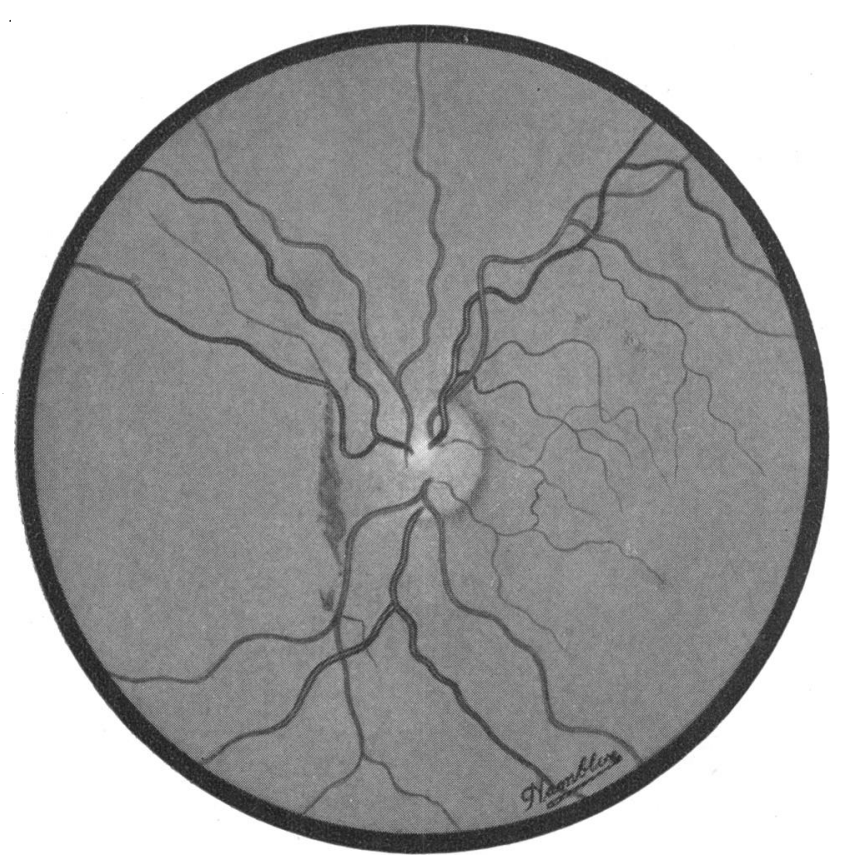

Drawing 18. Case 9.

Note angiod streaks in a case of Paget's disease. 
There are no angioid streaks, but the central haemorrhage and changes are typical of this class of choroidal disease. The changes were similar in both eyes.

DRAWING 19.

Note on CASE 10-Drawing 19. 
Urine.-No sugar, no albumen.

W.R.-Negative.

Differential blood count.-Polymorphs. 56 per cent.

Eosinophils 3 per cent., basophils 0 per cent., small lymphocytes 25 per cent., large lymphocytes 14 per cent., large hyaline cells 2 per cent.

Extensive choroidal atrophy with isolated haemorrhages; peculiar grey lines like obliterated vessels branching in irregular fashion and not connected with retinal arteries or veins and not resembling choroidal vessels. Bands of fibrous tissue proceeding outwards from atrophic area.

Further notes of the case see Trans. Ophthal. Soc. U.K., Vol XLVIII, p. 443, 1928.

The patient has since died. He lost his voice and the use of his right side two days before he died.

No other member of the family was seen.

See fundus drawing of right eye (No. 9).

The condition of the fundus was bilateral.

CaSe 6. (Mr. Humphrey Neame's Case. Ref. 8). Drawings 10, 11, 12.

A. D., male, aged 44 years.

Case shown at meetings of Section of Ophthalmology in 1922 and 1923.

June, 1922.-Right macula, retinal haemorrhage.

August, 1922. - Circular, grey-white, raised patch in upper macular region with old and recent haemorrhage.

September, 1922.- Retinitis circinata faintly seen and angioid streaks noted.

October, 1922.-Retinitis circinata well-defined.

December, 1923.-Disappearance of white exudate of retinitis circinata and replacement by black strands. Persistence of swelling near the centre of the macula but less prominent. Small recent haemorrhage. Angioid streaks much as before.

December, 1927.-Angioid streaks as before. The right macular region shows if anything more dead white pallor and diminution or absence of swelling, with wellmarked pigment proliferation overlying retinal vessels. The left macula is slightly mottled and has well-marked pigment proliferation chiefly above and to its nasal side.

Case 7. (Mr. Williamson-Noble's Case. Ref. 10). Drawings 13, 14.

Mrs. N., aged 40 years. ago.

October, 1929.- - R. eye. Commotio retinae following blow by tennis ball 9 years

Much scarring at macula.

Vision $=$ fingers at 1 metre.

Left eye as drawn.

Vision c. +0.5 D. sph. -0.25 D. cyl. $45^{\circ}=6 / 5$ full.

Birth normal. No family history of abnormal sight.

No history of fever or general disease.

No injury to left eye.

From her story the condition would appear to have been commented upon by an oculist in Jerusalem many years previously.

\section{Case 8. (Mr. Muirhead's Case. Ref. 9). Drawings 15, 16.}

A. E., coal miner, aged 30 years, 1928.

Vision Right $=6 / 6$ partly. Left, fingers at 15 inches.

Diagnosis.- (1) Optic atrophy ; (2) Angioid streaks; (3) Retinal degeneration; (4) Subhyaloid haemorrhages; (5) Changes at left macula.

Clinical History.-Misses an object on the floor unless he is particularly looking at it. Night vision very bad. Could not stand naked light. Slow adaptation on entering and leaving coal pit. In 1926, vision of left eye failed rapidly.

All his systems were examined and X-ray examination revealed delay in the appendix region. He has since been operated on for appendicitis.

Field white. R.E. slight general contraction. L. E. marked general contraction.

Central colour V. Right eye difficulty between blue and green, below No. 2 (Lister) L. E. Total central colour scotoma, relative paracentral. 
CASE 9. (Mr. Juler's Case). Drawings 17, 18.

E. R., aged 51 years, male.

December, 1923 . V. Right $6 / 60$ with -1.50 D. sph. -0.75 D. cyl. $=6 / 6$.

V. Left $6 / 12$ partly -0.75 D. sph. -0.75 D. cyl. at $45^{\circ}=6 / 6$ partly.

Has been told that he has acromegaly, but this has been denied by other medical men.

He has " horse" type of head with square forehead and prominent jaw, but says that this has been exactly the same since birth.

Takes the same size in hats as previously, no change in size of extremities.

Dr. C. P. Symonds reports in 1924 that he has Paget's disease.

Fundi.-Angioid streaks present in both eyes running beneath upper and lower nasal vessels. Left O.D. slightly blurred at upper and lower margins, but otherwise normal.

May, 1925.-Symptoms of migraine, vision as before. Angioid streaks as before.

Case 10. (Mr. T. Collyer Summers' Case. Ref. 11). Drawing 19.

Subhyaloid retinal haemorrhages in both eyes associated with Paget's disease.

Female, aged 57 years.

$\mathrm{X}$-rays show typical and advanced bony changes of Paget's disease.

The bony changes involved both upper and both lower extremities, the pelvis, skull and spine, leading to considerable deformity of legs and arms.

The blood calcium was normal.

Shown by D. Evan Bedford at the Association of Physicians Meeting, Summer, 1930.

\section{To summarize :-}

This choroidal disease has its onset in middle life, round about 40 years of age. It is not associated with any syphilitic, tuberculous, or septic cause, and is not inflammatory in origin, but primarily a vascular disease. It is probably an inherited disease, and often familial. It affects both eyes. The earlier symptoms are a pallor surrounding the O.D., fine pigment changes at the macula and central area and angioid streaks, without necessarily any loss of vision. The later symptoms are central macular haemorrhages and exudation, associated with retinitis circinata. These in turn tend to absorption, giving rise to extensive choroidal atrophy, with scattered gross pigmentation, and later still to retinitis proliferans. The same choroidal disease occurs without angioid streaks. If the association of angioid streaks with this form of choroidal disease be considered established, the-prognosis in cases showing angioid streaks should be very guarded even where there are full vision and no symptoms. They may exist for many years before any central haemorrhage occurs.

I am indebted to the authors of the cases, other than my own, for the use of their drawings and notes, also to Messrs. Hamblin

Note on Case 9.-Since the above was written, Mr. Juler has seen the patient again, and reports that the $\mathrm{V}$. $=\mathrm{Rt}$. 6/9. Left 6/6 partly. The streaks are definitely larger and more numerous. 
for the use of their collection of ophthalmic drawings, but for which I could not have got these cases together.

\section{REFERENCES}

* 1. Holloway, T. B.-Angioid streaks : a report concerning two cases. Trans. Amer. Ophthal. Soc., Vol. XXV, pp. 173-208, 1927.

2. Calhoun.-Trans. Amer. Ophthal. Soc., Vol. XXV, p. 209, 1927.

3. Spicer.-Oph. Sec. Proc. Roy. Soc. Med., Vol. VIII, 1915.

4. Doyne.-Trans. Ophthal. Soc. U.K., Vol IX, p. 128, 1889.

5. Verhoeff, F. H.-Presession Book of the Section of Ophthalmology of the American Medical Association. 1928.

6. Gayer-Morgan.--Oph. Sec. Roy. Soc. Med., Vol. XX, January, 1927.

7. Percival Hay.-Trans. Ophthal. Soc. U.K., Vol. XLVIII, p. 443.

8. Neame, Humphrey. - Macular degeneration after retinitis circinata. Oph. Sec. Roy. Soc. Med., Vol. XXI, December, 1927.

9. Muirhead.-Trans. Ophthal. Soc. U K., Vol. XLVIII, p. 446, 1928.

10. Williamson-Noble. - Hamblin's collection of ophthal. drawings.

11. Summers. Hamblin's collection of ophthal drawings.

* There is a full list of references given at the end of Holloway's paper on angioid streaks.

\section{ANNOTATION}

\section{Bust of Mr. MacCallan unveiled at Giza}

An interesting ceremony took place at Giza on March 13, when H. E. the High Commissioner of Egypt unveiled a bust of $\mathrm{Mr}$. MacCallan to commemorate his 20 years' service as Director of the Egyptian Ophthalmic Hospitals. This bust, an illustration of which is included here, through the courtesy of the artist, Mr. F. Doyle-Jones, A.R.B.S., has been subscribed for by Mr. MacCallan's friends, pupils and colleagues in the Egyptian ophthalmic service. It will be remembered that Mr. MacCallan retired from Egypt in 1923, and that an annotation dealing with his work there appeared in our columns early in 1924. At the present time it is only necessary to offer our congratulations to Mr. MacCallan that his pioneer work in Egypt should have been recognized by his foreign associates and pupils in this practical manner.

When Mr. MacCallan first entered on his work Egypt was indeed a land of darkness. Much has been accomplished to ameliorate this terrible state of affairs, and the good work is surely progressive. It will probably take years to bring the figures of Egyptian blindness within reasonable limits, but Mr. MacCallan will have the satisfaction of knowing that his work has been appreciated by all concerned with this ancient country: we hope that the bust will keep his memory green as long as 